\title{
LIPOXIGENASES E TEOR DE ÁCIDO LINOLÊNICO RELACIONADOS À QUALIDADE DE SEMENTES DE SOJA ${ }^{1}$
}

\author{
DARIO ALVES DE OLIVEIRA ${ }^{2}$, NEWTONDENIZPIOVESAN ${ }^{3}$, INÊS CHAMEL JOSÉ ${ }^{4}$, EVERALDO GONÇALVES DEBARROS ${ }^{5}$, DENISE CUNHA \\ FERNANDESDOS SANTOSDIAS ${ }^{6}$, MAURIILIOALVESMOREIRA ${ }^{7}$
}

\begin{abstract}
RESUMO - Os teores de ácidos graxos da fração óleo das sementes de soja não têm sido considerados na avaliação da qualidade das sementes em trabalhos de pesquisa recentes. O objetivo deste trabalho foi determinar o efeito da ausência de lipoxigenases e baixo teor de ácido linolênico na qualidade de sementes de soja colhidas em diferentes épocas após o estádio R8. Quatro "bulks" de sementes de soja foram formados, com as características: (a) presença de lipoxigenases e teor normal de ácido linolênico, (b) presença de lipoxigenases e baixo teor de ácido linolênico, (c) ausência de lipoxigenases e teor normal de ácido linolênico e (d) ausência de lipoxigenases e baixo teor de ácido linolênico. Sementes de cada "bulk" da geração F5 foram colhidas nos estádios R8, $\mathrm{R} 8+10, \mathrm{R} 8+20$ e R8+30 dias. A qualidade físiológica das sementes foi avaliada através dos testes de germinação, envelhecimento acelerado e índice de velocidade de emergência. Foi determinado também os teores de ácido linolênico das sementes. Sementes dos "bulks" com baixo teor de ácido linolênico apresentaram maior germinação e menor número de plântulas anormais após o estádio R8+20 dias. Sementes dos "bulks" com lipoxigenases apresentaram maior velocidade de emergência. O baixo teor de ácido linolênico presente na fração óleo da semente de soja favorece a produção de sementes de melhor qualidade e a presença de lipoxigenase favorece a maior velocidade de emergência de plântulas.
\end{abstract}

Termos para indexação: Glycine max, LOX, ácido graxo polinsaturado, qualidade fisiológica.

\section{LIPOXYGENASES, LINOLENICACIDCONTENTANDQUALITY OF SOYBEAN SEEDS}

\begin{abstract}
The fatty acid content of soybean seeds has not been considered when evaluating the quality of seeds in research work carried out so far. The objective was to determine the effects of absence of lipoxygenases and low linolenic acid content on seed quality after delayed harvest. Four different bulks were constructed: (a) seeds with lipoxygenase and normal linolenic acid content; (b) seeds with lipoxygenase and low linolenic acid content; (c) seeds without lipoxygenase and normal linolenic acid content and (d) seeds without lipoxygenase and low linolenic acid content. F5 seeds were harvested at the R8 stage and 10, 20 and 30 days after R8 stage. Seed physiological quality was evaluated by the standard germination test, accelerated aging test and emergence speed index. Seeds with low linolenic acid content presented higher seed quality as measured by the accelerated aging test. Seeds with lipoxygenase showed higher vigor as compared to those lacking these isozymes as determined by the emergence speed index.
\end{abstract}

Index terms: Glycine max, LOX, ácido graxo polinsaturado, physiological quality.

\footnotetext{
${ }^{1}$ Submetido em 30/08/2004. Aceito para publicação em 31/03/2005. Parte da tese apresentada pelo primeiro autor à Universidade Federal de Viçosa para obtenção do título de doutor em Fitotecnia. Órgão financiador: CNPq;

${ }^{2}$ DS, Professor do Departamento de Biologia Geral da Universidade Estadual de Montes Claros. 39480-082 Montes Claros, MG, Brasil. E-mail: dario.oliveira@unimontes.br;

${ }^{3}$ MS, Pesquisador do Instituto de Biotecnologia Aplicada à Agropecuária da Universidade Federal de Viçosa - BIOAGRO. 36571-000 Viçosa, MG, Brasil;
}

${ }^{4}$ MS Estudante de Doutorado em Ciência e Tecnologia de Alimentos da Universidade Federal de Viçosa. 36571-000 Viçosa, MG, Brasil;

${ }^{5} \mathrm{PhD}$, Professor do Departamento de Biologia Geral da Universidade Federal de Viçosa - BIOAGRO. 36571-000 Viçosa, MG, Brasil;

${ }^{6}$ DS, Professor adjunto do Departamento de Fitotecnia da Universidade Federal de Viçosa. 36571-000 Viçosa, MG, Brasil;

${ }^{7} \mathrm{PhD}$, Professor do Departamento de Bioquímica e Biologia Molecular da Universidade Federal de Viçosa - BIOAGRO. 36571-000 Viçosa, MG, Brasil. 


\section{INTRODUÇÃO}

Lipoxigenases são enzimas que catalisam a adição de oxigênio molecular aos ácidos graxos polinsaturados contendo o sistema cis, cis - 1,4 - pentadieno (Axelrod et al., 1981; Mack et al., 1987). As lipoxigenases (LOX) estão presentes nas sementes de soja na forma de três isoenzimas (LOX 1, 2 e 3). Os alelos que determinam a ausência dessas isoenzimas em sementes de soja são recessivos e possuem herança mendeliana simples. O loco L1 está ligado ao L2 e o loco L3 é independente (Kitamura et al., 1983).

No início da germinação de sementes de espécies ricas em óleo há um grande aumento de hidroperóxidos nos lipídios armazenados. Nestas sementes pode ser detectada a presença da enzima 13-lipoxigenase (13-LOX) na monocamada fosfolipídica dos corpos lipídicos. Esta enzima antecede a ação de lipases, sendo responsável pela oxidação na posição 13 da cadeia carbônica de um ácido graxo e tendo a capacidade de oxidar resíduos de ácidos graxos esterificados (Feussner et al., 2001).

$\mathrm{Na}$ fração óleo de sementes de soja, o ácido linoléico representa em torno de 57\%, enquanto que o ácido linolênico representa de 7 a 9\% (Kitamura, 1984). Os ácidos linoléico e linolênico destacam-se como os mais susceptíveis à degradação oxidativa enzimática e não enzimática (Anderson e Baker, 1983). A peroxidação dos ácidos graxos polinsaturados pela ação de lipoxigenases leva à produção de hidroperóxidos que por reações subsequentes produzem aldeídos e cetonas de cadeia curta (Lakoki et al., 1976; Axelrod et al., 1981; German e Kinsella, 1985).

Num modelo proposto, Wilson e McDonald (1986) consideram que a peroxidação de lipídios e a conseqüente formação de produtos secundários estão relacionadas com a deterioração das sementes. As sementes que possuem o lipídio como principal substância de reserva, quando armazenadas estão sujeitas a um lento e consistente ataque por oxigênio, formando hidroperóxidos, outros ácidos oxigenados e radicais livres.

Correlação positiva entre o número de duplas ligações do ácido graxo (linoléico e linolênico) e a formação de peróxidos foi obtida por Neff et al. (1992). Correlação negativa entre teores de ácido linolênico com a qualidade fisiológica de sementes de soja e também baixa associação entre atividade de lipoxigenases com a qualidade fisiológica das sementes observada por Trawatha et al. (1995a e 1995b).

Trabalhos de pesquisa têm sido realizados com o objetivo de determinar os efeitos da enzima lipoxigenase na qualidade fisiológica de sementes de soja (Queiroz, 1993; Oliveira, 1996; Dias, 1999; Queiróz, 2000). No entanto, teores de ácidos graxos da fração óleo das sementes não têm sido considerados nestas avaliações. Neste trabalho foi realizado retardamento da colheita no campo para observação da influência da presença ou ausência de lipoxigenase e dos teores de ácido linolênico na qualidade de sementes de soja. O objetivo deste trabalho foi avaliar a influência das isoenzimas lipoxigenases e do teor de ácido linolênico da fração óleo na qualidade de sementes de soja colhidas em diferentes épocas.

\section{MATERIAL E MÉTODOS}

O presente trabalho foi conduzido no campo experimental da Faculdade de Agronomia, no Laboratório de Análises de Sementes de Soja do Departamento de Fitotecnia e em Laboratórios do Instituto de Biotecnologia Aplicada à Agropecuária (BIOAGRO), na Universidade Federal de Viçosa (UFV).

O genótipo BARC-12 foi desenvolvido pelo USDA-ARS em Beltsville, MD (Leffel, 1994), possui baixo teor de ácido linolênico (6\%) e presença das izoenzimas lipoxigenases (LOX 1, 2 e 3). O genótipo Doko-TN (triplo-nulo) é uma linhagem avançada do Programa de Melhoramento de Soja do UFV/ BIOAGRO que possui teor normal (8\%) de ácido linolênico e ausência de lipoxigenases.

As sementes da geração $\mathrm{F} 1$ provenientes do cruzamento entre BARC-12 e Doko TN foram caracterizadas para a atividade de lipoxigenases (Oliveira et al., 1998) e semeadas em vasos, mantidos em casa de vegetação. As sementes da geração F2 foram colhidas e identificadas para presença de lipoxigenases por meio de testes colorimétricos (Suda et al., 1995) e determinação da atividade de lipoxigenases. Foi realizada, também, a determinação da composição de ácidos graxos da fração óleo por cromatografia gasosa, com a utilização de metodologia de Bubeck et. al. (1989) adaptada no laboratório do BIOAGRO. Em seguida, foram formados quatro "bulks" de sementes de acordo com a presença/ ausência de LOX e teores de ácido linolênico: (a) presença de lipoxigenase e teor normal de ácido linolênico, (b) presença de lipoxigenase e baixo teor de ácido linolênico, (c) ausência de lipoxigenase e teor normal de ácido linolênico e (d) ausência de lipoxigenase e baixo teor de ácido linolênico.

As sementes da geração F2 foram semeados em vasos, em casa de vegetação, conforme realizado para as sementes F1. As sementes das gerações F3 e F4 foram colhidas, novamente identificadas e separadas em "bulks", conforme 
as quatro características descritas anteriormente. As sementes F4 foram semeadas no campo e as sementes $\mathrm{F} 5$ foram colhidas nos estádios R8, R8 + 10, R8 +20 e R8 +30 dias. Neste trabalho foi realizada retardamento de colheita no campo para observação da influência da presença ou ausência de lipoxigenase e dos teores de ácido linolênico na qualidade de sementes de soja.

O loco L1 se encontra ligado ao loco L2, portanto para detecção de lipoxigenases pelo método colorimétrico não houve necessidade de analisar a isoenzima lipoxigenase $2 \mathrm{Na}$ extração das isoenzimas LOX 1 e 3 foram utilizadas entre cinco e $10 \mathrm{mg}$ de semente de soja raspada, envolvendo tegumento e cotilédones, em tubo de ensaio. Para a detecção das isoenzimas foi utilizado o método de Suda et al. (1995), de forma modificada e adaptada, no laboratório de proteína do BIOAGRO. O método utilizado para deteç̧ão de lipoxigenases foi não destrutivo e todas as sementes analisadas foram semeados para obtenção de posterior geração.

A atividade das lipoxigenases foi utilizada para identificação da presença/ausência de LOX 1 e 3 e para diferenciação das sementes heterozigotas para estas características.

A qualidade das sementes foi avaliada por meio dos testes de germinação, envelhecimento acelerado e índice de velocidade de emergência. Além disso, foram confirmadas as presenças/ausências de lipoxigenases e determinados os teores de ácido linolênico.

A viabilidade das sementes nos "bulks" foi avaliada pelo teste de germinação conforme as Regras para Análises de Sementes (Brasil, 1992). Utilizando-se quatro repetições de 50 sementes para cada "bulk", em cada época de colheita. No teste de envelhecimento acelerado foram utilizadas 200 sementes, suspensas em uma rede metálica e acondicionadas em caixas gerbox contendo $40 \mathrm{~mL}$ de água desmineralizada, mantidas em câmara B.O.D. a $41^{\circ} \mathrm{C}$ por 48 horas, conforme Krzyzanowski et al. (1991). Após esse período, quatro repetições de 50 sementes foram colocadas para germinar como descrito anteriormente e os resultados foram expressos em porcentagem de plântulas normais e anormais.

$\mathrm{O}$ teste de emergência de plântulas foi realizado em substrato de areia em casa de vegetação, com a utilização de quatro repetições de 50 sementes. Neste teste, foi avaliado o índice de velocidade de emergência das plântulas, computandose o número de plântulas emergidas diariamente, até que a emergência permanecesse constante. Para a determinação do índice de velocidade de emergência (IVE), foi utilizada a fórmula proposta por Maguire (1962):
IVE $=\frac{N_{1}}{D_{1}}+\Lambda+\frac{N_{n}}{D_{n}}$, onde: $N 1=$ número de plantas emergidas na primeira contagem; $\mathrm{D} 1$ = número de dias para a primeira contagem; $\mathrm{Nn}=$ número de plantas emergidas na última contagem; e $\mathrm{Dn}=$ número de dias para a última contagem.

A emergência de plântulas normais foi computada no quinto dia após a semeadura e os resultados foram expressos em porcentagem de plântulas normais.

As determinações da presença de ácido linolênico e a sua quantificação foram realizadas segundo Bubeck et al. (1989), com a utilização de cromatografia gasosa. As temperaturas utilizadas para a análise cromatográfica foram $225^{\circ} \mathrm{C}$ na coluna; $245^{\circ} \mathrm{C}$ no injetor e $280^{\circ} \mathrm{C}$ no detector. $\mathrm{O}$ gás de arraste utilizado foi o nitrogênio com fluxo de $1,3 \mathrm{~mL} \cdot \mathrm{min}^{-1}$. Foram analizadas três repetições por tratamento e os resultados expressos em porcentagem de ácido linolênico.

O delineamento experimental utilizado foi o inteiramente casualizado, em esquema fatorial, considerando-se como fatores os "bulks" e as épocas de colheita. A partir da análise de variância foram realizados desdobramentos com a análise dos diferentes "bulks", fixando as diferentes épocas de colheita. Para a verificação da normalidade do conjunto de dados, foi realizado o teste de Lilliefors e, aqueles que não seguiram a distribuição normal foram transformados em arc sen $\sqrt{\% / 100}$ (Gomes, 1990). O efeito dos tratamentos foi analisado por regressão polinomial.

\section{RESULTADOS E DISCUSSÃO}

Nas sementes com teor normal de ácido linolênico e ausência de lipoxigenases foi observada queda do índice de velocidade de emergência após o estádio R8. A ausência de lipoxigenases pode ter desfavorecido a mobilização de lipídios. Resultados semelhantes e de mais fácil interpretação podem ser observados nos dados provenientes da porcentagem de plântulas normais após o quinto dia de implantação do teste de índice de velocidade de emergência (Figura 1). Sementes com lipoxigenases, independentemente do teor de ácido linolênico, apresentaram maior velocidade de emergência que sementes com ausência de lipoxigenases.

Os teores de ácido linolênico determinados nas sementes da geração F5 estiveram em torno de $4 \%$ e variaram entre 6 e $8 \%$ para os "bulks" com teores normais de ácido linolênico (Figura 2). Variação significativa do teor de ácido linolênico 


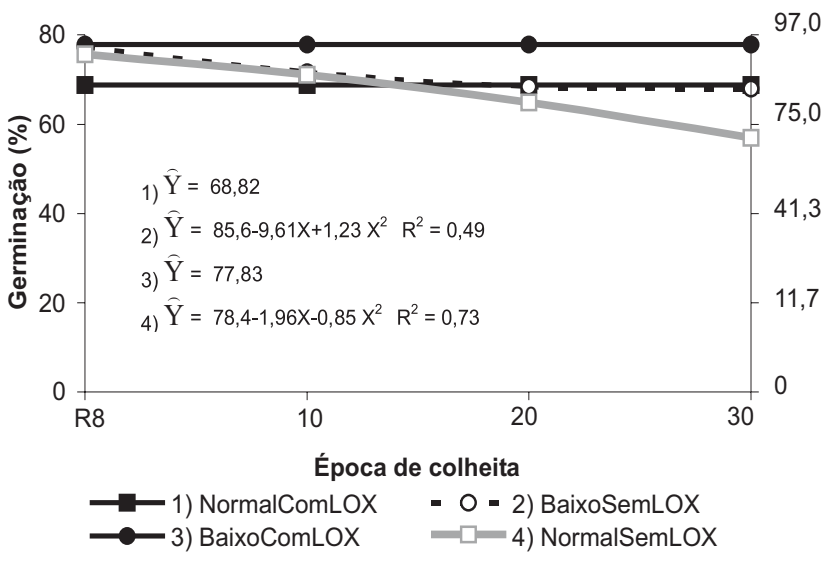

FIGURA 1. Plântulas normais (\%) obtidas no teste de germinação dos quatro"bulks" de sementes de soja avaliados, em quatro épocas de colheita, a partir do estádio R8.

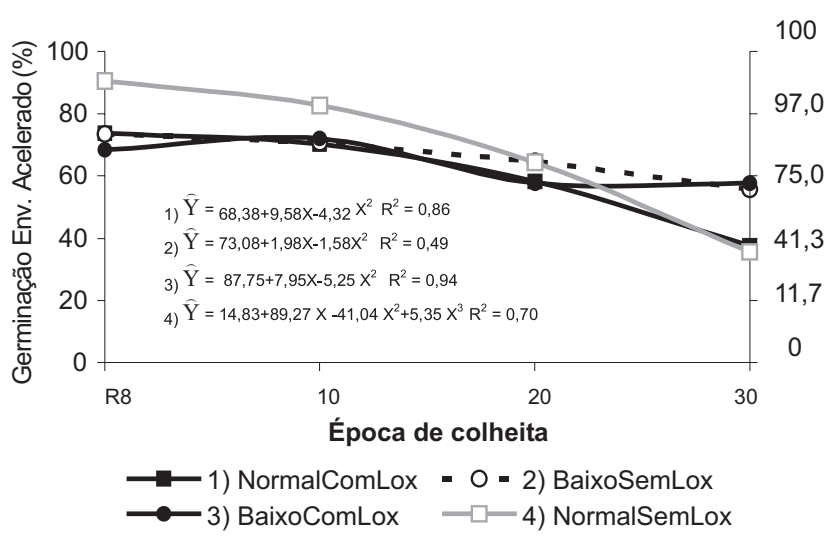

FIGURA 2. Germinação (\%) obtida no teste de envelhecimento acelerado dos quatro "bulks" de sementes de soja avaliados, em quatro épocas de colheita, a partir do estádio R8.

com o retardamento de colheita no campo foi observada somente no "bulk" com teor normal de ácido linolênico e presença da enzima lipoxigenase.

No teste de germinação foram obtidas diferenças significativas entre os "bulks" de sementes, no entanto não foi observada interação entre o tratamento e os "bulks". Foi observada queda mais significativa na germinação de sementes no "bulk" com teor normal de ácido linolênico e ausência de lipoxigenases, enquanto que os "bulks" com baixo teor de ácido linolênico e ausência de lipoxigenases e com teor normal de ácido linolênico e presença de lipoxigenase apresentaram comportamentos semelhantes em relação a germinação de sementes após o estádio R8+20 dias. Sementes do "bulk" com baixo teor de ácido linolênico e ausência de lipoxigenases apresentaram maior porcentagem de germinação após o estádio

\section{R8 (Figura 3).}

No teste de envelhecimento acelerado, as sementes de todos os "bulks" apresentaram redução do percentual de germinação quando submetidas ao estresse de alta temperatura e alta umidade relativa. Em todos os materiais genéticos foram observadas reduções significativas no vigor das sementes à medida que estas eram mantidas por mais tempo no campo (Figura 4). Redução mais acentuada na qualidade das sementes com teor normal de ácido linolênico foi observada após o estádio R8+20 dias. Trinta dias após o estádio R8, os "bulks" com teor normal de ácido linolênico apresentaram porcentagem de germinação cerca de $20 \%$ menor do que "bulks" de sementes com baixo teor de ácido linolênico após o envelhecimento acelerado. Esse comportamento indica menor vigor das sementes dos "bulks" com teores normais de ácido linolênico em relação aos "bulks" com baixo teor de ácido linolênico. A menor porcentagem de plântulas anormais obtida no teste de envelhecimento acelerado evidencia o maior vigor das sementes com baixo teor de ácido linolênico em relação às sementes com teor normal de ácido linolênico (Figura 4). Na colheita realizada dez dias após o estádio R8, os "bulks" de sementes com teor normal de ácido linolênico já apresentavam número maior de plântulas anormais em relação aos "bulks" com baixo teor de ácido linolênico. Na colheita realizada trinta dias após o estádio R8, os “bulks" de sementes com teor normal de ácido linolênico apresentaram porcentagem em torno de $20 \%$ maior de plântulas anormais.

Wilson e McDonald (1986) consideram que a peroxidação dos lipídios com formação de produtos secundários é um

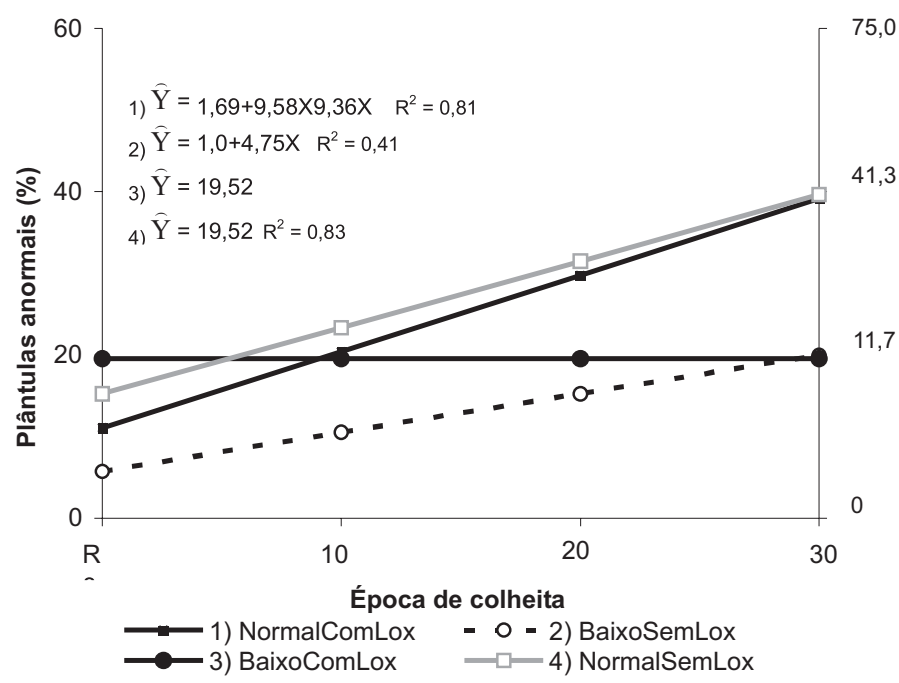

FIGURA 3. Plântulas anormais (\%) obtidas no teste de envelhecimento acelerado nos "bulks" avaliados, em quatro épocas de colheita, a partir do estádio R8. 


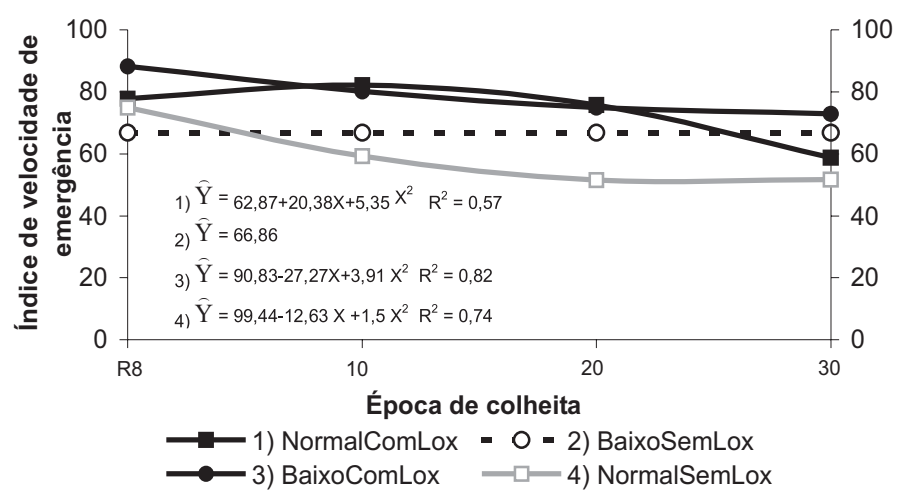

FIGURA 4. Índice de velocidade de emergência (IVE) obtido nos quatro "bulks"de sementes de soja, em quatro épocas de colheita, a partir do estádio R8.

dos principais processos responsáveis pela deterioração das sementes. A velocidade de oxidação depende do grau de insaturação do ácido graxo, quanto maior for o número de insaturações do ácido graxo, maior será a susceptibilidade à oxidação e o produto formado é o hidroperóxido do ácido graxo (Araújo, 1989). Segundo Anderson e Baker (1983), os ácidos linolêico e linolênico são mais susceptíveis à degradação oxidativa e não oxidativa. Neff et al. (1992) observaram correlação positiva entre duplas ligações dos ácidos graxos (linoléico e linolênico) com a formação de peróxidos e de compostos voláteis.

Os dados obtidos nos testes de germinação e envelhecimento acelerado (avaliação das plântulas normais e anormais) sugerem que sementes com maior teor de ácidos graxos insaturados são mais susceptíveis à peroxidação, podendo estar mais predispostas à deterioração quando expostas a condições desfavoráveis no campo. Estes resultados estão de acordo com Trawata et al. (1995a e 1995b), que verificaram menor viabilidade e vigor em sementes com maiores teores dos ácidos linolênico e linoléico, armazenadas à temperatura ambiente.

A velocidade de oxidação dos ácidos graxos é altamente acelerada pelas lipoxigenases existentes em sementes de muitas espécies, especialmente em soja (Araújo, 1989). Nos resultados dos testes de germinação e envelhecimento acelerado não foi observada associação entre lipoxigenases e qualidade das sementes. A maior queda na qualidade das sementes, verificada na colheita 30 dias após o estádio R8, esteve associada ao teor do ácido linolênico. Resultados semelhantes foram obtidos por Trawatha et al. (1995a) no qual a ausência de uma, duas ou três isoenzimas lipoxigenases não influenciou na qualidade de sementes de soja armazenadas.

Maior velocidade de emergência de plântulas foi observada para os "bulks" de sementes com presença de lipoxigenases em relação aos "bulks" com ausência de lipoxigenases até o estádio de colheita R8+20 dias (Figura 5). Após esse período, foi observada redução do índice de velocidade de emergência de plântulas do "bulk" de sementes com lipoxigenase e teor normal de ácido linolênico.

A manutenção de maior velocidade de emergência até o estádio $\mathrm{R} 8+20$ dias pode estar relacionada à facilidade na mobilização de lipídios pelas lipoxigenases. O comportamento de queda após este estádio pode estar relacionado à produção de quantidade expressiva de compostos secundários tóxicos nestas sementes. Conforme observado na Figura 6 a mobilização de lipídios pode ter ocasionado aumento do teor de ácido linolênico após o estádio R8+20 dias,

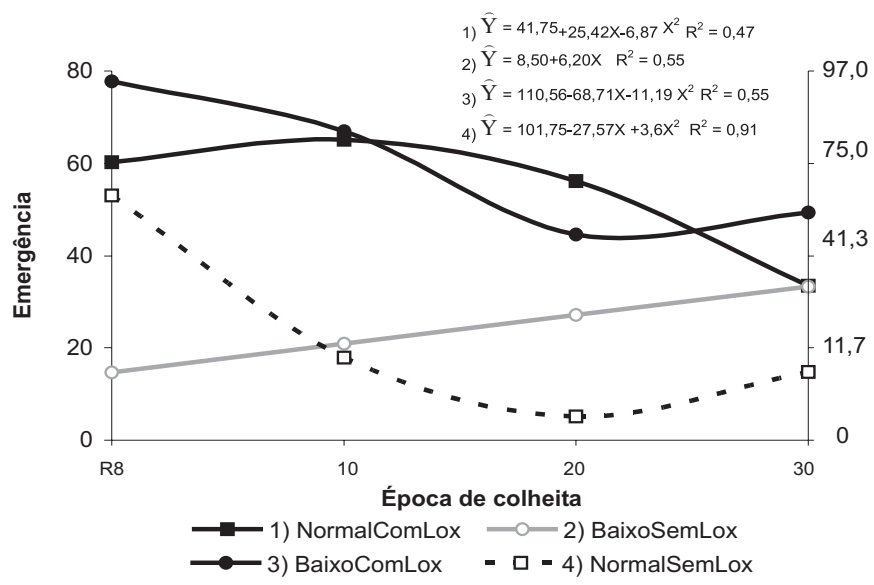

FIGURA 5. Emergência (\%) obtida no quinto dia do teste de índice de velocidade de emergência dos quatro "bulks" de sementes de soja, avaliados em quatro épocas de colheita, a partir do estádio R8.

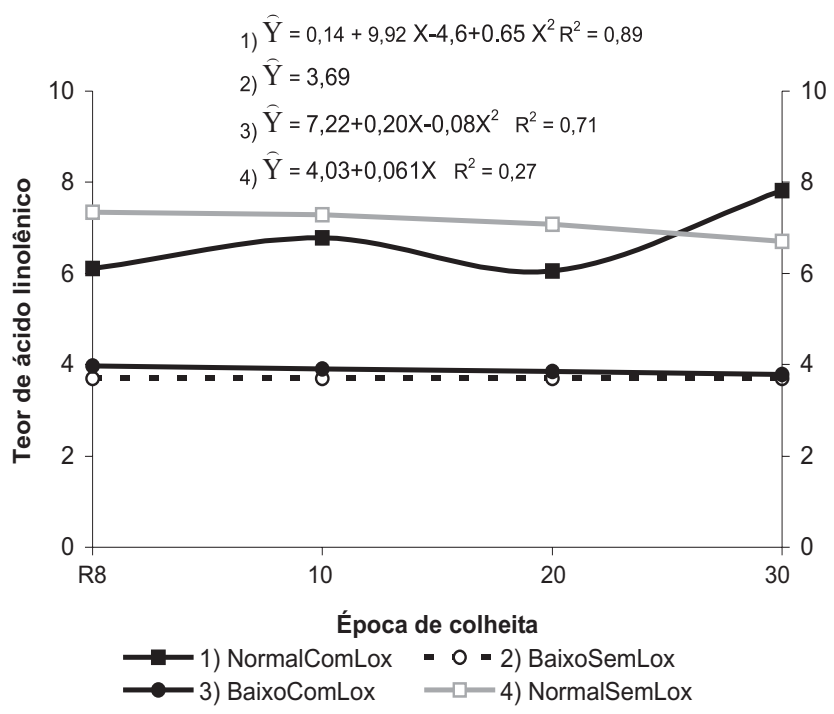

FIGURA 6. Teor de ácido linolênico (\%) obtido nos quatro "bulks" de sementes de soja avaliados, em quatro épocas de colheita, a partir do estádio $\mathbf{R 8}$. 


\section{CONCLUSÕES}

O baixo teor de ácido linolênico, presente na fração óleo da semente de soja, favorece a produção de sementes de melhor qualidade e a presença de lipoxigenase favorece maior velocidade de emergência de plântulas.

\section{AGRADECIMENTOS}

Agradecemos ao Instituto de Biotecnologia Aplicada à Agropecuária (BIOAGRO-UFV) pela oportunidade de realização deste trabalho e ao Conselho Nacional de Desenvolvimento Científico e Tecnológico (CNPq), pela bolsa de estudo concedida ao primeiro autor, durante o curso de doutorado em Fitotecnia.

\section{REFERÊNCIAS}

ANDERSON, J.D.; BAKER, J.E. Deterioration of seeds during aging. Phytopathology, Saint Paul, v.73, n.2, p. 321-325, 1983.

ARAÚJO, J.M.A. Oxidação de lipídios. Viçosa: UFV, 1989. 22p. (Boletim de extensão, 283).

AXELROD, V.; CHEESBROUGH, T.M.; LAASKO, S. Lipoxigenase from soybeans. Methods In Enzymology, New York, v.71, p.441$451,1981$.

BRASIL. Ministério da Agricultura. Secretaria Nacional de Defesa Agropecuária. Regras para análises de sementes. Brasília, SNDA/DNDV/CLAV, 1992.365p.

BUBECK, D.M.; FEHR, W.R.; HAMMOND, E.G. Inheritance of palmitic and stearic acid mutants of soybean. Crop Science, Madison, v.29, p.652-656, 1989.

DIAS, A.C.P. Atividade de lipoxigenases durante a germinação e qualidade fisiológica de sementes de soja. 1999. 53f. Dissertação (Mestrado em Fitotecnia) - Universidade Federal de Viçosa, Viçosa, 1999.

FEUSSNER, I.; KÜHN, H.; WASTERNACK, C. Lipoxygenasedependent degradation of storage lipids. Plant Science, Columbus, v.6, n.6, p.268-273, 2001.

GERMAN, J.B.; KINSELLA, J.E. Lipid oxidation in fish tissue. Enzymatic initiation via lipoxygenase. Journal of Agricultural and Food Chemistry, Easton, v.33, p.680-683, 1985.

GOMES, F.P. Curso de estatística experimental. 13.ed. Piracicaba: ESALQ/USP, 1990. 468p.

HILDEBRAND, D.F.; HAMILTON-KEMP, T.R.; LEGG, C.S.; BOOKJANS, G. Current Topics in Plant Biochemistry and Phisiology, v.7, p.201-219, 1988.

KITAMURA, K.; DAVIES, C.S.; KAIZUMA, N.; NIELSEN, N.C. Genetic analysis of a null-allele for lipoxygenase-3 in soybean seeds. Crop Science, Madison, v.23, p.924-927, 1983.
KITAMURA, K. Biochemical of lipoxigenase lacking mutantes, L1-Less, L2-Less and L3-Less soybeans. Agricultural and Biological Chemistry, Tokyo, v.48, n.9, p.2339-2346, 1984.

KRZYZANOWSKI, F.C.; FRANÇA NETO, J.B.; HENNING, A.S. Relato dos testes de vigor disponíveis para as grandes culturas. In: Informativo ABRATES, Brasília, v.1, n.2, p.15-50, 1991.

LAKOKI, J.W.; EMKEN, E.A.; LAW, J.H.; KEZON, F. Kinetic analysis of action of soybean lipoxygenase on linolenic acid. Journal of Biological Chemistry, Bethesda, v.251, p.6001-6006, 1976.

LEFFEL, R.C. Registration of BARC-12 a low linolenic acid soybean germplasm line. Crop Science, Madison, v.34, p.1426$2427,1994$.

MACK, A. J.; PETERMAN, T.K.; SIEDOW, J.N. Current Topics in Biological and Medical Research, v.13, p.127-154, 1987.

MAGUIRE, J.D. Speed of germination-aid in selection and evaluation for sedling emergence and vigour. Crop Science, Madison, v.2, p.176-177, 1962.

NEFF, W.E.; SELKE, E.; MOUNTS, T.L.; RINSH, W.; FRANKEL, E.N.; ZEINTOUN. M.A.M. Effect of triacylglycerol composition and strutures on oxidative stability of oils from selected soybean germoplasm. JACOS, v.69, n.2, p.111-118, 1992.

OLIVEIRA, D.A. Qualidade fisiológica e produção de aldeídos em sementes de linhagens com ausência de lipoxigenases e em sementes de cultivares de soja. 1996. 67f. Dissertação (Mestrado em Fitotecnia) - Universidade Federal de Viçosa, Viçosa, 1996.

OLIVEIRA, D.A.; PIOVESAN, N.D.; MORAES, R.M.A.; ROCHEBOIS, GB.; OLIVEIRA, M.G.A.; BARROS, E.G.; MOREIRA, M.A. Identification of the three genotipic classes for soybean lipoxygenases 1 and 3 based on enzimatic activity. Biotechnology Techniques., v.12, p.71-74, 1998.

QUEIROZ, L.R. Produção de aldeídos na germinação e qualidade de sementes de genótipos de soja com ausência de lipoxigenases. 1993. 53f. Dissertação (Mestrado em Fitotecnia) - Universidade Federal de Viçosa, Viçosa, 1993.

QUEIRÓZ, T.F.N. Qualidade fisiológica de genótipos de soja sem lipoxigenases. 2000. 53f. Dissertação (Mestrado em Fitotecnia) Universidade Federal de Viçosa, Viçosa, 2000.

SUDA, I.; HAJIKA. M.; NISHIBA, Y.; FURUTA, S.; IGITA, K. Simple and rapid method for the selective detection of individual lipoxygenase isozymes in soybean seeds. Journal of Agricultural and Food. Chemmistry, Easton, v.43, p.742-747, 1995.

TRAWATHA, S.E.; TEKRONY, D.M.; HILDEBRAND, D.F. Soybean lipoxygenase mutants and seed longevity. Crop Science, Madison, v.35, p.862-868, 1995a.

TRAWATHA, S.E.; TEKRONY, D.M.; HILDEBRAND, D.F. Soybean lipoxygenase mutants and seed longevity. Crop Science, Madison, v.35, p.1415-1422, 1995b.

WILSON JR., D.O.; McDONALD JR., M.B. A convenient volatile aldehyde assay for measuring seed vigour. Seed Science and Technology, Zürich, v.14, n.2, p.259-268, 1986.

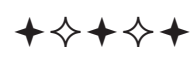

